\title{
Photoluminescent properties of oxidized stochiometric and carbon-rich amorphous $\mathrm{Si}_{1-\mathrm{x}} \mathrm{C}_{\mathrm{x}}: \mathrm{H}$ films
}

\author{
A.V. Vasin ${ }^{1}$, Y. Ishikawa ${ }^{2}$, A.V. Rusavsky ${ }^{1}$, A.N. Nazarov ${ }^{1}$, A.A. Konchitz ${ }^{1}$, V.S. Lysenko ${ }^{1}$ \\ ${ }^{1}$ V. Lashkaryov Institute of Semiconductor Physics, 03028 Kyiv, Ukraine \\ ${ }^{2}$ Japan Fine Ceramics Center, Nagoya, 456-8587 Japan
}

\begin{abstract}
Near-stochiometric and carbon-rich a-Si $i_{1-x} \mathrm{C}_{\mathrm{x}}: \mathrm{H}$ thin films were deposited using the magnetron sputtering of $\mathrm{Si}$ target in $\mathrm{Ar} / \mathrm{CH}_{4}$ gas mixture. As-deposited nearstochimetric $(x=0.5)$ sample showed weak blue photoluminescence $(P L)$, while PL of as-deposited carbon-rich $(\mathrm{x}=0.7)$ sample was 20 times stronger and white in color. The films were annealed in pure argon, wet argon, and dry oxygen at $450{ }^{\circ} \mathrm{C}$ for $30 \mathrm{~min}$. The intensity of $\mathrm{PL}$ in $\mathrm{a}-\mathrm{Si}_{1-\mathrm{x}} \mathrm{C}_{\mathrm{x}}: \mathrm{H}$ layers were enhanced by the factor from 2 to 12 after annealing in dependence on the annealing atmosphere. The strongest oxidation and strongest light emission were observed in carbon-rich series $(x=0.7)$ after annealing in oxidizing atmosphere. Structural properties of the films were characterized by infra-red absorption spectroscopy, ellipsometry and electron paramagnetic resonance. The effect of carbon enrichment of $\mathrm{a}-\mathrm{Si}_{1-\mathrm{x}} \mathrm{C}_{\mathrm{x}}: \mathrm{H}$ films and annealing atmosphere on the evolution of photoluminescence and local interatomic bonding structure in annealed material were studied and analyzed. It has been found that main effects of thermal treatments is strong enhancement of photoluminescence accompanied by formation of $\mathrm{Si}: \mathrm{C}-\mathrm{H}_{n}$ and $\mathrm{Si}-\mathrm{O}_{\mathrm{x}} \mathrm{C}_{\mathrm{y}}$ bonding. The strongest oxidation effect as well as strongest photoluminescence were observed in carbon-rich a-SiC:H films.
\end{abstract}

Keywords: $a-\mathrm{Si}_{1-\mathrm{x}} \mathrm{C}_{\mathrm{x}}: \mathrm{H}$, photoluminescence, ellipsometry and electron paramagnetic resonance, infra-red absorption spectroscopy.

Manuscript received 18.09.14; revised version received 08.12.14; accepted for publication 19.02.15; published online 26.02.15.

\section{Introduction}

Development of new white light emitting materials synthesized using the processes compatible with common silicon based technology is of great interest especially in the field of flat displays and indication panels. Recently, it has been demonstrated that carbon incorporated silicon oxide nanostructured materials exhibit a strong white photoluminescence (PL). Intriguing is that white PL was demonstrated by $\mathrm{SiOC}$ materials fabricated by quite different methods, namely: SiOC thin films deposited by thermal chemical vapor deposition (TCVD) [1], atmospheric pressure microplasma jet deposition [2], magnetron sputtering depo- sition [3], $\mathrm{C}^{+}$implantation into $\mathrm{SiO}_{2}$ [4-6], chemical vapor deposition technique [7], carbonization/oxidation of porous silicon [8,9], sol-gel method [10].

The origin of white light emission in these materials is still unclear but common features of the composition and PL properties indicate a common lightemission mechanism. It is obvious that photoluminescence is associated with incorporation of carbon in silicon oxide matrix but more detailed structural identification is under debate. In this paper, we analyze correlations of PL and structural properties of thin films fabricated by combination of magnetron sputtering deposition and thermal annealing/oxidation of hydrogenated amorphous silicon-carbon alloy films $\left(a-\mathrm{Si}_{1-\mathrm{x}} \mathrm{C}_{\mathrm{x}}: \mathrm{H}\right)$. 


\section{Experimental}

a-Si $i_{1-\mathrm{x}} \mathrm{C}_{\mathrm{x}}: \mathrm{H}$ films were deposited on $p$-type $40 \mathrm{Ohm} \cdot \mathrm{cm}$ $\mathrm{Si}(100)$ and glass substrates by reactive dc-magnetron sputtering of a silicon target in $\mathrm{Ar} / \mathrm{CH}_{4}$ gas mixture by analogy with [11] and [12]. Using this sputtering configuration, the films with different carbon content can be deposited by varying the substrate-target distance. The larger is the distance, the smaller incorporation of deposited silicon atoms is and, correspondingly, the larger relative contribution of carbon incorporated with hydrocarbon radicals from operation gas. Two samples with $x=0.5(320 \mathrm{~nm}$ thick) and $x=0.7(780 \mathrm{~nm}$ thick) were deposited at the substrate temperature $200{ }^{\circ} \mathrm{C}$. Composition of the films was determined using Augerelectron spectroscopy with $\mathrm{SiC}(6 \mathrm{H})$ crystal as a reference sample. The volume density of the layers measured by weighing the substrate before and after deposition was $2.2 \pm 0.1 \mathrm{~g} / \mathrm{cm}^{3} \quad(x=0.5)$ and $1.6 \pm 0.1 \mathrm{~g} / \mathrm{cm}^{3} \quad(x=0.7)$. After the deposition, the samples were annealed at atmospheric pressure in the flow of dry Ar, wet-Ar and dry $\mathrm{O}_{2}$ flow at $450{ }^{\circ} \mathrm{C}$ for $30 \mathrm{~min}$.

\section{Results and discussion}

PL of as-deposited and annealed a- $\mathrm{Si}_{1-\mathrm{x}} \mathrm{C}_{\mathrm{x}}: \mathrm{H}$ samples was measured at room temperature using excitation by $351 \mathrm{~nm}$ line of $\mathrm{Ar}^{+}$laser. The refractive index was calculated using spectral ellipsometry measurements. The local bonding structure in the films was studied by Fourier-Transform Infra-Red spectroscopy (FTIR).
Paramagnetic defects were analyzed using electron paramagnetic resonance (EPR) in the X-band with 100$\mathrm{kHz}$ modulation of magnetic field.

Weak PL band with the maximum intensity near $420 \mathrm{~nm}$ was detected in the as-deposited a-Si $\mathrm{Si}_{0.5} \mathrm{C}_{0.5}: \mathrm{H}$ film (Fig. 1a, spectrum 1). Annealing at $450{ }^{\circ} \mathrm{C}$ for $30 \mathrm{~min}$ in dry argon results in appearance of the emission band with the maximum intensity near $510 \mathrm{~nm}$, while the blue component seems to be unchanged (Fig. 1a, spectrum 2). Oxidation by wet argon and oxygen resulted in further development of the "green" band, but the integrated intensity of PL in the sample annealed in wet argon was 5 times higher (Fig. 1c). The narrow features at 700 and $727 \mathrm{~nm}$ available in all the spectra are laser satellites. The amplitude of these laser lines can be used for rough estimation of the relative PL intensity in different samples.

As-deposited carbon-rich a-Si $\mathrm{i}_{0.3} \mathrm{C}_{0.7}: \mathrm{H}$ film emitted broad PL band white in color with strongly modulated spectrum (Fig. 1b, spectrum 1). We unambiguously attribute modulating features of the spectra to interference effects because: (1) these features are shifted with changing of the angle between sample plane and optical slip of monochromator; (2) these features disappeared after mechanical roughening of the film surface by diamond past (grain size of $20 \mathrm{~nm}$ ). The maximum intensity of PL in the as-deposited sample was estimated to be within the range $500 \ldots 550 \mathrm{~nm}$. The PL intensity increased strongly after annealing in dry Ar, while the spectral shape of PL was almost unchanged (Fig. 1b, spectrum 2). Annealing in wet argon and dry
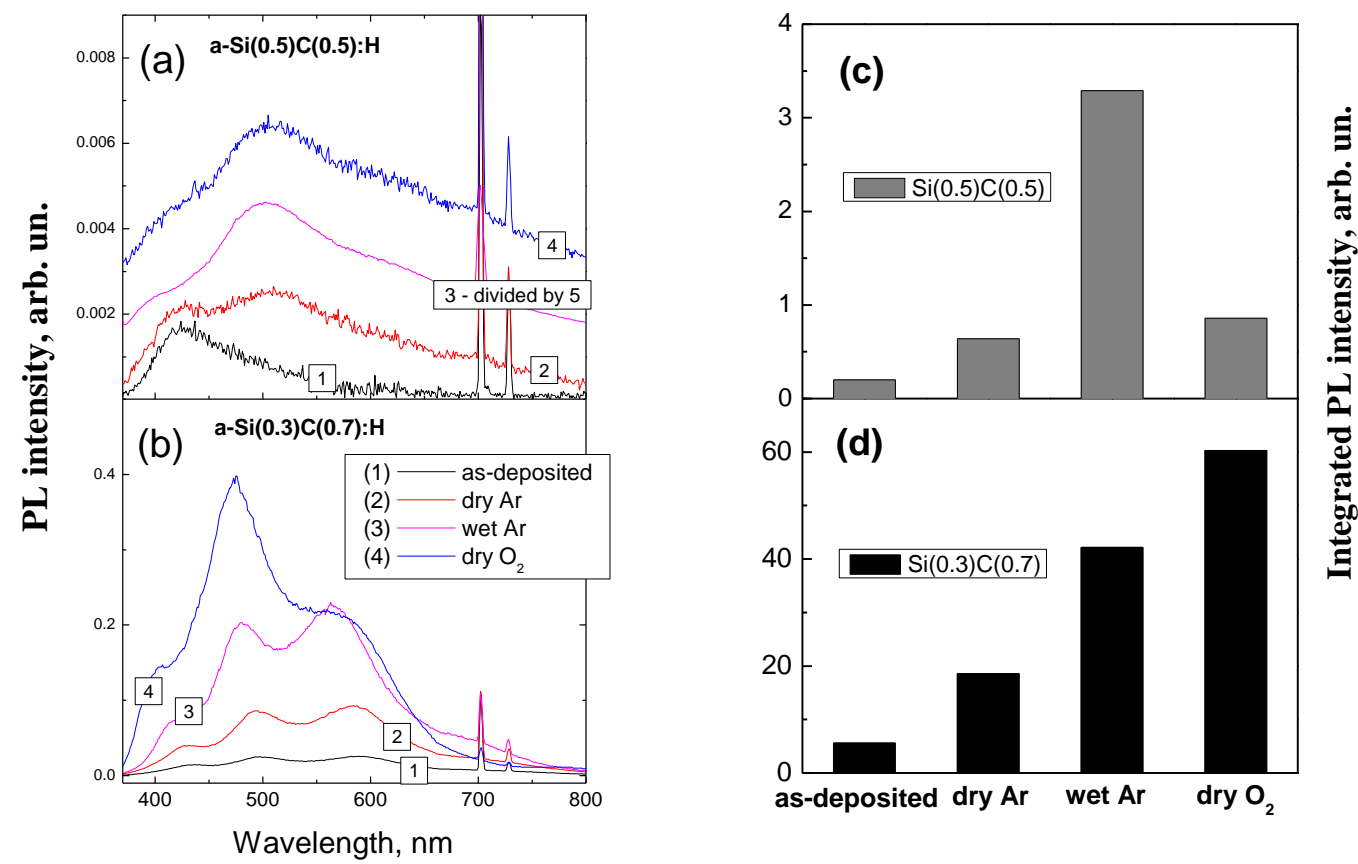

Fig. 1. PL spectra of as-deposited (spectrum 1) and annealed (2 - dry Ar, 3 - wet $\left.\mathrm{Ar}, 4-\operatorname{dry} \mathrm{O}_{2}\right)$ a- $\mathrm{Si}_{0.5} \mathrm{C}_{0.5}: \mathrm{H}(a)$ and a$\mathrm{Si}_{0.3} \mathrm{C}_{0.7}: \mathrm{H}(b)$ films; integrated PL intensities of as-deposited and annealed a-Si $\mathrm{Si}_{0.3} \mathrm{C}_{0.7}: \mathrm{H}(c)$ and a-Si ${ }_{0.5} \mathrm{C}_{0.5}: \mathrm{H}(d)$ films. 


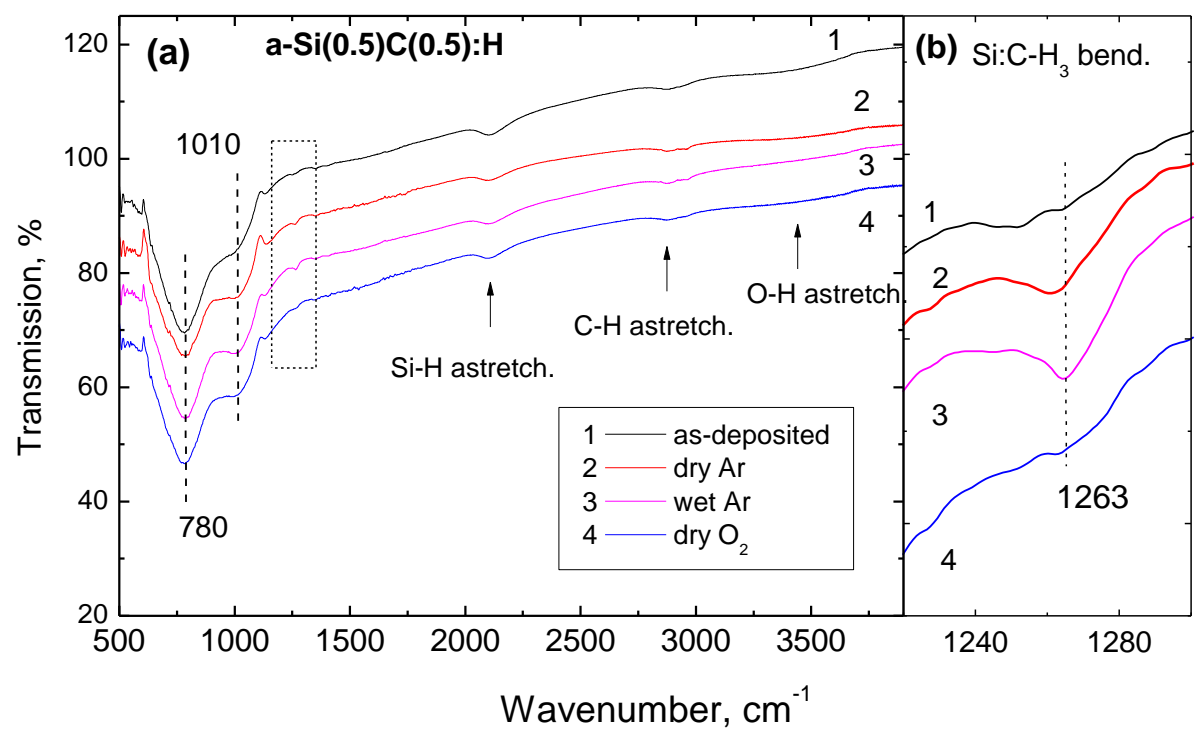

Fig. 2. (a) - FTIR spectra of a-Si $\mathrm{Si}_{0.5} \mathrm{C}_{0.5}: \mathrm{H}:(1)$ - as-deposited, and annealed in dry $\operatorname{Ar}(2)$, wet $\operatorname{Ar}(3)$ and dry $\mathrm{O}_{2}(4) ;(b)$ - scaledup spectral range $1220 \ldots 1300 \mathrm{~cm}^{-1}$ (selected by dashed quadrangle in $(a)$ ).

oxygen resulted in further increase of PL intensity (Fig. 1d) and the obvious blue shift of the intensity distribution caused by oxygen treatment (Fig. 1b, spectra 3 and 4).

Transmission FTIR spectra of as-deposited and annealed $\mathrm{a}-\mathrm{Si}_{1-\mathrm{x}} \mathrm{C}_{\mathrm{x}}: \mathrm{H}$ films are presented in Fig. 2. The spectrum of as-deposited sample is composed by strong absorption bands at $780 \mathrm{~cm}^{-1}$ (Si-C stretching) and $1010 \mathrm{~cm}^{-1}$ (deformation $\mathrm{C}-\mathrm{H}_{\mathrm{n}}$ and/or stretching $\mathrm{Si}-\mathrm{O}-$ $\mathrm{Si})$, and weaker absorption bands at $2100 \mathrm{~cm}^{-1}\left(\mathrm{Si}-\mathrm{H}_{\mathrm{n}}\right.$ stretching) and $2690 \ldots 3000 \mathrm{~cm}^{-1}\left(\mathrm{C}\left(\mathrm{sp}^{3}\right)-\mathrm{H}_{\mathrm{n}}\right.$ stretching $)$. A traces of absorption were found at about $1260 \mathrm{~cm}^{-1}$ (deformation modes of $\mathrm{Si}: \mathrm{C}-\mathrm{H}_{3}$ bonds) and within range $3000 \ldots 3500 \mathrm{~cm}^{-1}$ (O-H stretching). The weak narrow spectral features at 608 and $1100 \mathrm{~cm}^{-1}$ are due to imperfect subtraction of the absorption of $\mathrm{Si}$ substrate (oxygen contaminations in Si wafer). FTIR absorption peaks and corresponding vibration modes assigned in $\mathrm{a}-\mathrm{Si}_{\mathrm{x}} \mathrm{C}_{\mathrm{y}} \mathrm{O}_{\mathrm{z}}: \mathrm{H}$ films are presented in Table.

The absorption band at $1010 \mathrm{~cm}^{-1}$ in a- $\mathrm{Si}_{1-\mathrm{x}} \mathrm{C}_{\mathrm{x}}: \mathrm{H}$ films is commonly ascribed to rocking/waging vibration modes in $\mathrm{CH}_{2}$ radicals bonded to silicon atoms $-\mathrm{Si}-\mathrm{CH}_{2}-\mathrm{Si}$ [23-27]. But it is well known that the main absorption band in silicon sub-oxide $\mathrm{SiO}_{\mathrm{x}}(x<2)$ is also located at $1000 \ldots 1400 \mathrm{~cm}^{-1}$ depending on $x$ [20]. Residual oxygen contamination in our films was estimated using Auger electron spectroscopy to be up to $7 \ldots 10$ at.\%, so that the contribution of $\mathrm{Si}-\mathrm{O}$ vibrations should be taken into account. Unfortunately, it is not possible to separate correctly hydrogen- and oxygenrelated absorption bands, but, basing on our previous experience [12], we assume that hydrogen-related contribution dominates in as-deposited samples. From Fig. $2 \mathrm{a}$, one can see that the relative intensity of this band is increased after thermal treatments regardless of annealing atmosphere (spectra 2,3,4). Annealing in dry and wet Ar resulted in development of the $\mathrm{Si}: \mathrm{C}-\mathrm{H}_{3}-$ related band at $1260 \mathrm{~cm}^{-1}$ (Fig. 2b, spectra 2, 3), while the intensity of $\mathrm{Si}-\mathrm{H}_{\mathrm{n}}\left(2100 \mathrm{~cm}^{-1}\right)$ and $\mathrm{C}-\mathrm{H}_{\mathrm{n}}$ $\left(2690 \ldots 3000 \mathrm{~cm}^{-1}\right)$ decreased.

Table. Identification of IR absorption bands in a-SiC:H/ a-SiOC:H thin films.

\begin{tabular}{|c|c|c|c|}
\hline \multirow{2}{*}{$\begin{array}{c}\text { Absorption } \\
\text { band } \\
\left(\mathrm{cm}^{-1}\right)\end{array}$} & \multirow{2}{*}{ Attribution } & \multicolumn{2}{|c|}{ References } \\
\hline & & Theory & Experiment \\
\hline 450 & $\mathrm{Si}-\mathrm{O}-\mathrm{Si}$, rock. & [13] & [13], [20-22] \\
\hline 780 & $\mathrm{Si}-\mathrm{C}$, str. & [14-17] & [20], [23-28] \\
\hline $780-800$ & $\mathrm{C}-\mathrm{H}_{3}$, bend. & [16-18] & [27], [29] \\
\hline 800 & $\mathrm{Si}-\mathrm{O}-\mathrm{Si}$, str. & [13] & [13], [20-22] \\
\hline 940 & $\mathrm{Si}-\mathrm{OH}$, str. & & [30-31] \\
\hline \multirow[b]{2}{*}{1010} & $\mathrm{CH}_{2}$ rock/wag & [16-18] & [23-27] \\
\hline & $\begin{array}{l}\mathrm{Si}-\mathrm{O} \text { in } \mathrm{SiO}_{\mathrm{x}} \\
(\mathrm{x}<2) \text {, str. }\end{array}$ & & [20], [32] \\
\hline $1060-1200$ & $\mathrm{Si}-\mathrm{O}-\mathrm{Si}$, str. & [13] & [13], [20-22] \\
\hline 1260 & $\mathrm{Si}: \mathrm{CH}_{3}$, bend. & [16-18] & $\begin{array}{c}\text { [23-28], [33], } \\
{[34]}\end{array}$ \\
\hline 1700 & $\mathrm{C}=\mathrm{O}$, str. & & [33] \\
\hline 2100 & $\mathrm{Si}-\mathrm{H}_{\mathrm{n}}$, str. & [16-19] & [19], [23-28] \\
\hline $2700-3000$ & $\begin{array}{l}\mathrm{C}\left(\mathrm{sp}^{3}\right)-\mathrm{H}_{\mathrm{n}} \\
\text { str. }\end{array}$ & [16-18] & [23-28], [33] \\
\hline $3000-3700$ & $\mathrm{O}-\mathrm{H}$, str. & & {$[21],[35],[36]$} \\
\hline
\end{tabular}




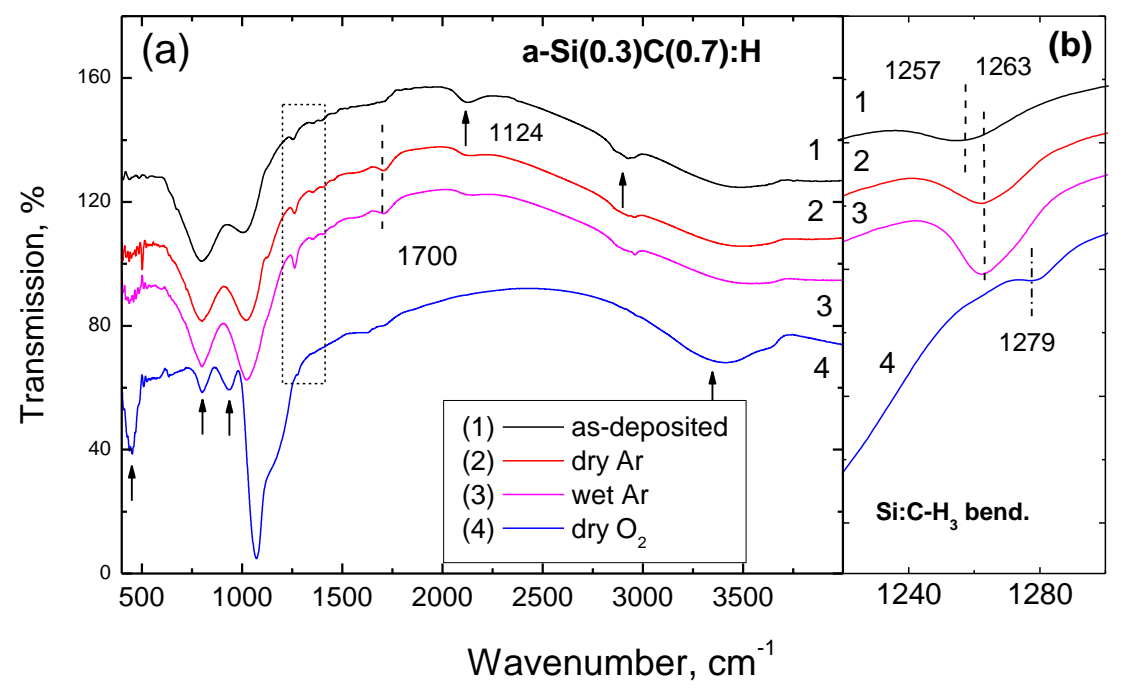

Fig. 3. (a) - FTIR spectra of a- $\mathrm{Si}_{0.3} \mathrm{C}_{0.7}: \mathrm{H}:(1)$ - as-deposited, annealed in dry $\operatorname{Ar}(2)$, wet $\operatorname{Ar}(3)$ and dry $\mathrm{O}_{2}(4)$; (b) - scaled-up spectral range $1220 \ldots 1300 \mathrm{~cm}^{-1}$ (selected by dashed quadrangle in $(a)$ ).

FTIR spectra of $\mathrm{a}-\mathrm{Si}_{0.3} \mathrm{C}_{0.7}: \mathrm{H}$ films are shown in Fig. 3a. The main absorption bands were found to be centered near 790 and $1010 \mathrm{~cm}^{-1}$, correspondingly. The relative intensity of $1010 \mathrm{~cm}^{-1}$ band as well as $\mathrm{Si}: \mathrm{C}-\mathrm{H}_{3}$ bending $\left(1256 \mathrm{~cm}^{-1}\right)$ and $\mathrm{C}-\mathrm{H}_{\mathrm{n}}$ stretching bands $\left(2800 \ldots 3000 \mathrm{~cm}^{-1}\right)$ is much stronger in the carbon-rich sample than that in $\mathrm{a}-\mathrm{Si}_{0.5} \mathrm{C}_{0.5}: \mathrm{H}$ indicating larger contribution of carbon-hydrogen bonds. The $\mathrm{OH}-$ related absorption band at $3500 \mathrm{~cm}^{-1}$ is also much stronger.

The intensity of 1010 and $1256 \mathrm{~cm}^{-1}$ bands was increased after annealing in dry and wet argon (Figs. 3a and $3 b$ ). Comparing Fig. $3 a$ and Fig. 3b, one can find the direct correlation for the intensities of these bands. Absorption intensity of $\mathrm{Si}-\mathrm{H}_{\mathrm{n}}$ and $\mathrm{C}-\mathrm{H}_{\mathrm{n}}$ stretching vibration bands decreased after annealing in dry and wet $\mathrm{Ar}$, and completely vanished after thermal treatment in oxygen. Obvious absorption at about $1700 \mathrm{~cm}^{-1}$ due to $\mathrm{C}=\mathrm{O}$ stretching (sym./asym.) vibrations [33] was observed after annealing in dry and wet argon (Fig. 3a, spectra 3 and 4).

Annealing of a- $\mathrm{Si}_{0.3} \mathrm{C}_{0.7}: \mathrm{H}$ film in oxygen resulted in strong oxidation of the material. Several oxygen related bands are now present in the spectrum (Fig. 3a, spectrum 4): $450 \mathrm{~cm}^{-1}$ (rocking $\mathrm{Si}-\mathrm{O}-\mathrm{Si}$ ), $802 \mathrm{~cm}^{-1}$ (symmetrical stretching $\mathrm{Si}-\mathrm{O}-\mathrm{Si}), 940 \mathrm{~cm}^{-1}(\mathrm{Si}-\mathrm{OH}$ stretching), $1063 \mathrm{~cm}^{-1}$ (in-phase asymmetrical stretching $\mathrm{Si}-\mathrm{O}-\mathrm{Si}$ ) with characteristic shoulder at $1160 \mathrm{~cm}^{-1}$ (outof-phase asymmetrical stretching), and $3000 \ldots 3700 \mathrm{~cm}^{-1}(\mathrm{O}-\mathrm{H}$ stretching $)$. It is logical to assign the weak band at $1279 \mathrm{~cm}^{-1}$ (Fig. 3b, spectrum 4) to $\mathrm{Si}-\mathrm{CH}_{3}$ band strongly shifted to the high frequency side due to increase of bonding polarity caused by oxygen incorporation [37]. The weak but well detectable double band within the range $1540 \ldots 178 \mathrm{~cm}^{-1}$ (peaks near 1600 and $1700 \mathrm{~cm}^{-1}$ ) is attributed to $\mathrm{C}=\mathrm{C}$ and $\mathrm{C}=\mathrm{O}$ bonds, respectively [33].

Electron paramagnetic resonance measurements (EPR) were performed at room temperature in the $X$ band employing $100-\mathrm{kHz}$ field modulation. The single EPR line with $g$-factor $2.0026( \pm 0.0002)$ was detected in the as-deposited samples. No change of $g$-factor was observed after thermal treatments. The concentration of paramagnetic centers $N_{s}$ in the as-deposited a- $\mathrm{Si}_{0.5} \mathrm{C}_{0.5}: \mathrm{H}$ and $\mathrm{a}-\mathrm{Si}_{0.3} \mathrm{C}_{0.7}: \mathrm{H}$ films was calculated to be about $2 \cdot 10^{20}$ and $5 \cdot 10^{19} \mathrm{~cm}^{-3}$, respectively. Variation of the spin concentration in the films after annealing was similar, i.e. gradual decrease after annealing in sequence (dry Ar) - (wet Ar) - (dry $\left.\mathrm{O}_{2}\right)$.

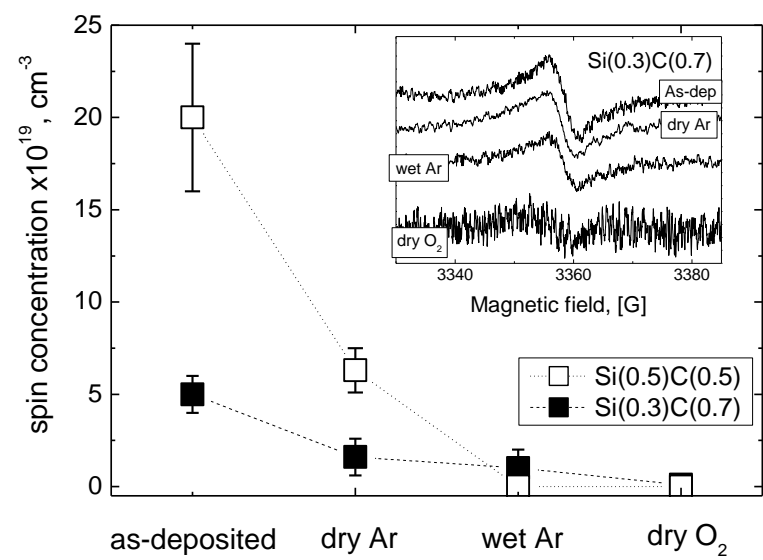

Fig. 4. Concentration of paramagnetic centers $N_{s}$ in asdeposited and annealed a- $\mathrm{Si}_{0.5} \mathrm{C}_{0.5}: \mathrm{H}$ and a- $\mathrm{Si}_{0.3} \mathrm{C}_{0.7}: \mathrm{H}$ series. Inset represents EPR spectra $\mathrm{Si}_{0.3} \mathrm{C}_{0.7}: \mathrm{H}$ series. 


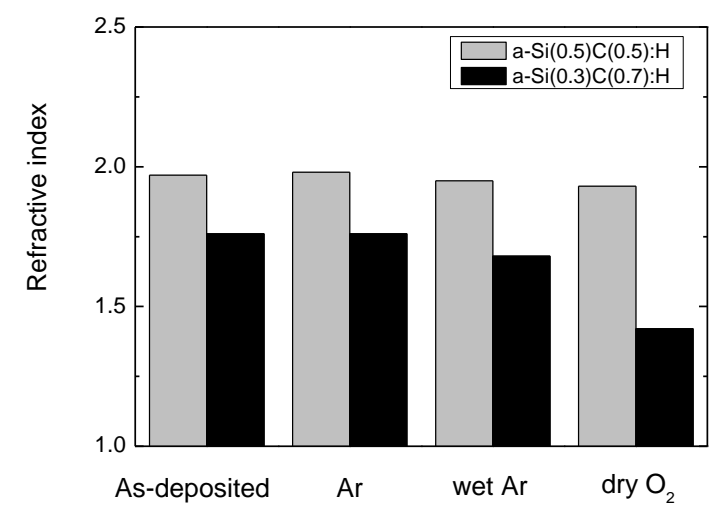

Fig. 5. Refractive index of as-deposited and annealed $\mathrm{a}-\mathrm{Si}_{0.5} \mathrm{C}_{0.5}: \mathrm{H}$ and $\mathrm{a}-\mathrm{Si}_{0.3} \mathrm{C}_{0.7}: \mathrm{H}$ series.

Calculation of the refractive index was performed using ellipsometry measurement in frame of the threelayer model (air/a-Si $i_{1-x} \mathrm{C}_{\mathrm{x}}: \mathrm{H} / \mathrm{c}-\mathrm{Si}$ ). The calculated refractive indexes of all the samples at the $500-\mathrm{nm}$ wavelength are presented in Fig. 5. The refractive index of the as-deposited near-stochiometric a- $\mathrm{Si}_{0.5} \mathrm{C}_{0.5}: \mathrm{H}$ film is about 2.0, which is considerably lower than that of crystalline $\mathrm{SiC}\left(n_{\mathrm{SiC}}=2.5\right)$ due to the lower density. Increase of the carbon content in the as-deposited film up to $x=0.7$ resulted in decrease of the refractive index down to 1.8. This is quite consistent with the density of films: about $2.2 \mathrm{~g} \cdot \mathrm{cm}^{-3}$ for near-stochiometric films and about $1.6 \mathrm{~g} \cdot \mathrm{cm}^{-3}$ for carbon-rich samples, which is significantly lower than $3.2 \mathrm{~g} \cdot \mathrm{cm}^{-3}$ for crystalline $\mathrm{SiC}$. No change in the refractive index was observed after annealing in dry argon, while decrease of the refractive index down to 1.9 was observed in a- $\mathrm{Si}_{0.5} \mathrm{C}_{0.5}: \mathrm{H}$ series after oxidation treatments. More significant decrease down to 1.7 and 1.4 was observed in carbon-rich series after thermal treatments in water vapor and oxygen, respectively.

The reduced density of carbon-rich a-SiC:H films is mostly associated with enhanced porosity of the carbon-rich structure [16]. Enhancement of nanoporosity due to development of termination of structural network by $-\mathrm{CH}_{\mathrm{n}}$ radicals during film growth is quite similar to that of a-SiOC:H films [38].

It was widely reported that decrease of the carbon content $x$ in a- $\mathrm{Si}_{1-\mathrm{x}} \mathrm{C}_{\mathrm{x}}: \mathrm{H}$ films in a broad range results in increase of the refractive index from 1.8..2.1 in carbonrich to $3.4 \ldots 3.8$ in silicon-rich species [24, 39-40]. This variation is obviously related with variation of relative contribution of $\mathrm{C}-\mathrm{C}, \mathrm{Si}-\mathrm{C}$ and $\mathrm{Si}-\mathrm{Si}$ bonds as well as nanoporosity of the structure.

It is worth noting that FTIR spectra indicate strong oxidation of carbon-rich series by dry oxygen in contrast to much weaker oxidation by water vapor. It is well known that oxidation rate of crystalline silicon carbide by water vapor is considerably higher than that by oxygen [41]. Detailed comparative study of oxidation effects in a-SiC and a-SiC:H caused by thermal annealing in water vapor and oxygen ambient was presented in [42]. The authors suggested that strong oxidation efficiency of oxygen in a-SiC: $\mathrm{H}$ is related with its high reactivity against carbon precipitates (i.e. $\mathrm{C}-\mathrm{C}$ bonds, hydrocarbon radicals, carbon clusters) natively available in hydrogenated amorphous silicon-carbon alloy films.

In Fig. 2, we see that PL efficiency in the films is related to (1) composition of as-deposited layer, (2) thermal effects (annealing in inert atmosphere, e.g. dry argon) and (3) oxidation effects. From the "classical" viewpoint, PL efficiency in amorphous VIgroup semiconductors (a-Si:H, a-C:H, a-SiC:H) is mainly determined by competition of radiative recombination from the conduction band tail to the valence band one (tail-to-tail transition) and nonradiative recombination path through mid-gap paramagnetic defect states [25]. The efficiency of radiative recombination in this model is reversely proportional to the concentration of non-radiative recombination centers associated mainly with paramagnetic dangling bonds.

The concentration of paramagnetic defects of $10^{20} \mathrm{~cm}^{-3}$ observed in as-deposited films is too high for effective radiative recombination through the tail-to-tail mechanism, so that blue light emission in as-deposited a- $\mathrm{Si}_{0.5} \mathrm{C}_{0.5}: \mathrm{H}$ films may be hardly assigned to recombination in the amorphous $\mathrm{SiC}$ matrix. Moreover, the optical band gap value derived from optical absorption measurements of this film on a glass substrate is close to $2.5 \mathrm{eV}$ that is significantly lower than the energy of PL ( $2.9 \mathrm{eV})$. We suggest that blue emission is associated with $\mathrm{SiO}_{\mathrm{x}}$ structural fragments available in asdeposited films due to residual oxygen contamination. The photon energy of PL band with the maximum intensity near $510 \mathrm{~nm}(2.4 \mathrm{eV})$ that arose after annealing is close to the optical band gap value, so that this band may be assigned to tail-to-tail recombination in the amorphous $\mathrm{SiC}$ network.

Comparing evolution of the PL intensity (Fig. 1) and concentration of paramagnetic defects (Fig. 4) in a$\mathrm{Si}_{0.5} \mathrm{C}_{0.5}: \mathrm{H}$ series, one can find no correlation. Moreover, comparing the PL intensity and concentration of paramagnetic centers in the a- $\mathrm{Si}_{0.5} \mathrm{C}_{0.5}: \mathrm{H}$ sample annealed in dry $\operatorname{argon}\left(N_{s}\right.$ is about $\left.6 \cdot 10^{19} \mathrm{~cm}^{-3}\right)$ and in the asdeposited a- $\mathrm{Si}_{0.3} \mathrm{H}_{0.7}: \mathrm{H}$ sample $\left(N_{s}\right.$ is about $\left.4 \cdot 10^{19} \mathrm{~cm}^{-3}\right)$, one can see that the PL intensity differs by 10 times, while the concentration of paramagnetic centers remains almost the same. It is obvious from these observations that the concentration of paramagnetic defects is not the only parameter determining the PL efficiency in a-Si $i_{1-x} C_{x}: H$. In the previous report [12], it was suggested that the PL efficiency in $\mathrm{a}-\mathrm{Si}_{1-\mathrm{x}} \mathrm{C}_{\mathrm{x}}: \mathrm{H}$ films can be increased by enhancement of spatial localization of photo-excited electron-hole pairs caused by increasing the concentration of $\mathrm{C}-\mathrm{H}$ bonds and corresponding increase of spatial fluctuations of the interatomic potential. In frame of this hypothesis, one can reasonably suggest that introducing $\mathrm{Si}-\mathrm{O}$ bonds would also increase 
fluctuations of this potential and enhances localization of photo-excited electron-hole pairs in the SiC network.

From Fig. 2b, one can see that the absorption band at $1263 \mathrm{~cm}^{-1}$ is the strongest one after annealing in wet argon. Taking into account obvious incorporation of oxygen due to interaction with water vapor, one may expect the strongest localization in this sample that is in good agreement with the highest PL intensity. After annealing in oxygen, the $1263-\mathrm{cm}^{-1}$ band is very weak, so that localization is mainly determined by oxygen incorporation, and PL intensity is lower.

The interferential feature in PL spectra of asdeposited a-Si $\mathrm{Si}_{0.3} \mathrm{C}_{0.7}: \mathrm{H}$ does not allow correct determination of the maximum intensity in the PL band, but rough estimation is about $550 \mathrm{~nm}(2.3 \mathrm{eV})$ for the asdeposited sample, while the optical band gap of this sample is about $2.7 \mathrm{eV}$. Combination of the effects of passivation of paramagnetic centers and enhancement of localization by $\mathrm{C}-\mathrm{H}$ and $\mathrm{Si}-\mathrm{O}$ bonds well explains increase of the PL intensity after annealing in dry and wet argon, but it is not the case after oxygen treatment, when almost full oxidation is observed (Fig. 3, spectrum 4). The PL spectrum is strongly changed and obviously shifted to blue region after annealing in dry oxygen (Fig. 1b, spectrum 4), so that one may reasonably expect that light emission happens not in amorphous $\mathrm{SiC}$ matrix. FTIR spectra identify the structure of oxidized film as silicon oxide matrix with some incorporation of carbon precipitates, consequently PL can be attributed presumably to both of these structural domains.

Photoluminescence of undoped nanostrucutred silica are commonly considered in terms of optically active point defects (reviewed in [45]). But photon emission of these defects in the visible spectral range is associated with the triplet transition $\left(\mathrm{T}_{1} \rightarrow \mathrm{S}_{0}\right)$, i.e. "phosphorescence", that is the natively slow process with a characteristic decay time of micro- and milliseconds, or even seconds. However, time-resolved measurements showed that the PL decay time in oxidized carbon-rich series is of about 10 nanoseconds.

Direct correlation of the broad band PL intensity and concentration of $\mathrm{Si}-\mathrm{O}-\mathrm{C}$ bonding configuration in a-SiOC thin films was demonstrated in [1]. The concentration of $\mathrm{Si}-\mathrm{O}-\mathrm{C}$ bonds was evaluated using the IR absorption band at $440 \mathrm{~cm}^{-1}$. In [2], the same authors developed their hypothesis and suggested that the oxygen vacancy in $\mathrm{Si}-\mathrm{O}-\mathrm{C}$ bridges also contributes to broad band light emission.

Carbon nanoclusters are also to be considered as a possible source of visible light emission. Recently, it was demonstrated that nanosized carbon particles in the form of 3D nanodots, 2D graphene nanodots and 2D-3D graphene oxide (GO) nanodots synthesized under proper conditions exhibit an effective visible photoluminescence with the decay time of the order of several nanoseconds [46-48].

\section{Conclusions}

More detailed studies are necessary to identify the light emission mechanism reliably. In summary, thermal and oxidation effects on photoluminescence in nearstochiometric and carbon-rich a-SiC:H films deposited using dc-magnetron sputtering have been studied. It has been found that the main effect of thermal treatment is strong enhancement of photoluminescence accompanied by formation of $\mathrm{Si}: \mathrm{C}-\mathrm{H}_{\mathrm{n}}$ and $\mathrm{Si}-\mathrm{O}_{\mathrm{x}} \mathrm{C}_{\mathrm{y}}$ bonding. The strongest oxidation effects as well as strongest white photoluminescence were observed in carbon-rich a$\mathrm{SiC}: \mathrm{H}$ films.

\section{References}

1. S. Gallis, V. Nikas, H. Suhag, M. Huang, and A.E. Kaloyeros, White light emission from amorphous silicon oxycarbide $\mathrm{a}-\mathrm{SiC}_{\mathrm{x}} \mathrm{O}_{\mathrm{y}}$ thin films: Role of composition and postdeposition annealing // Appl. Phys. Lett. 97, 081905 (2010).

2. Y. Ding, H. Shirai, White light emission from silicon oxycarbide films prepared by using atmospheric pressure microplasma jet // J. Appl. Phys. 105, 043515 (2009).

3. S. Hayashi, M. Kataoka, and K. Yamamoto, Photoluminescence spectra of carbon clusters embedded in $\mathrm{SiO}_{2} / /$ Jpn. J. Appl. Phys. Part 2, 32, p. L274 (1993).

4. Y.H. Yu, S.P. Wong, and I.H. Wilson, Visible photoluminescence in carbon-implanted thermal $\mathrm{SiO}_{2}$ films // phys. status solidi $(a), \mathbf{1 6 8}$, p. 531 (1998).

5. J. Zhao, D.S. Mao, Z.X. Lin, B.Y. Jiang, Y.H. Yu, X.H. Liu, H.Z. Wang, and G.Q. Yang, Intense short-wavelength photoluminescence from thermal $\mathrm{SiO}_{2}$ films co-implanted with $\mathrm{Si}$ and $\mathrm{C}$ ions // Appl. Phys. Lett. 73, p. 1838 (1998).

6. X.D. Zhou, F. Ren, X.H. Xiao, J.X. Xu, Z.G. Dai et al., Origin of white light luminescence from $\mathrm{Si}^{+} / \mathrm{C}^{+}$sequentially implanted and annealed silica // J. Appl. Phys. 111, 084304 (2012).

7. S.Y. Seo, K.S. Cho, and J.H. Shin, Intense bluewhite luminescence from carbon-doped silicon-rich silicon oxide // Appl. Phys. Lett. 84, p. 717 (2004).

8. A. Vasin, Y. Ishikawa, N. Shibata, J. Salonen, and V.-P. Lehto, Photoluminescence from carbonincorporated silicon oxide fabricated by preferential oxidation of silicon in nano-structured Si:C layer // Jpn. J. Appl. Phys. 46, p. L465 (2007).

9. Y. Ishikawa, A. Vasin, J. Salonen et al., Color control of white photoluminescence from carbon incorporated silicon oxide // J. Appl. Phys. 104, 083522 (2008).

10. A. Karakuscu, R. Guider, L. Pavesi, and G.D. Soraru, Broad-band tunable visible emission of sol-gel derived SiBOC ceramic thin films // J. Am. Ceram. Soc. 92, p. 2969 (2009). 
11. A.V. Vasin, S.P. Kolesnik, A.A. Konchits, V.I. Kushnirenko, V.S. Lysenko, A.N. Nazarov, A.V. Rusasky and S. Ashok, Effects of hydrogen bond redistribution on photoluminescence of a-SiC:H films under thermal treatment // J. Appl. Phys. 99, 113520 (2006).

12. A.V. Vasin, S.P. Kolesnik, A.A. Konchits, A.V. Rusavsky, V.S. Lysenko, A.N. Nazarov, Y. Ishikawa, and Y. Koshka, Paramagnetic defects and light-emission of carbon-rich a-SiC:H films // J. Appl. Phys. 103, 123710 (2008).

13. C.T. Kirk, Quantitative analysis of the effect of disorder-induced mode coupling on infrared absorption in silica // Phys. Rev. B, 38, p. 1255 (1988).

14. R. Reitano, G. Foti, Oscillator strength and effective charge in amorphous silicon carbon alloy // Solid State Communs. 115, p. 375-378 (2000).

15. J. Leszczynski, Handbook of Computational Chemistry. Springer, p. 1430, 2012.

16. Sh.Y. Lin, S.T. Chang, Variation of vibrational local modes and electronic states of hydrogenated amorphous silicon carbide under thermal annealing // J. Phys. Chem. Solids, 59(9), p. 1399-1405 (1998).

17. B.K. Ghosh, B.K. Agrawal, Vibrational structure of hydrogenated amorphous silicon carbide alloys // phys. status solidi (b), 147, p. 97 (1988).

18. B.K. Agrawal, P.S. Yadav, B.K. Ghosh, Vibrational excitations in $\mathrm{a}-\mathrm{Si}_{1-\mathrm{x}} \mathrm{C}_{\mathrm{x}}: \mathrm{H}$ alloys // J. Non-Cryst. Solids, 114, p. 519-521 (1989).

19. D.V. Tsu, G. Lucovsky, and B.N. Davidson, Effects of the nearest neighbors and the alloy matrix on $\mathrm{SiH}$ stretching vibrations in the amorphous $\mathrm{SiO}_{\mathrm{x}}: \mathrm{H}(0<\mathrm{x}<2)$ alloy system // Phys. Rev. B, 40, p. 1795-1805 (1989).

20. D.M. Wolfe, B.J. Hinds, F. Wang, G. Lucovsky, B.L. Ward, M. Xu, R.J. Nemanich, and D.M. Maher, Thermochemical stability of siliconoxygen-carbon alloy thin films: A model system for chemical and structural relaxation at $\mathrm{SiC}-\mathrm{SiO}_{2}$ interfaces // J. Vac. Sci. Technol. A, 17(4), p. 21702177 (1999).

21. G. Das, G. Mariotto, A. Quaranta, Microstructural evolution of thermally treated low-dielectric constant SiOC:H films prepared by PECVD // J. Electrochem. Soc. 153(3), p. F46-F51 (2006).

22. J.V. Ryana, C.G. Pantano, Synthesis and characterization of inorganic silicon oxycarbide glass thin films by reactive rf-magnetron sputtering // J. Vac. Sci. Technol. A, 25(1), p. 153-159 (2007).

23. H. Weider, M. Cardona and C.R. Guarnierl, Vibrational spectrum of hydrogenated amorphous Si-C films // phys. status solidi (b), 92, p. 99 (1979).

24. Y. Catherine, G. Turban, Infrared absorption of hydrogenated amorphous Si:C and Ge:C films // This Solid Films, 70, p. 101-104 (1980).
25. J. Bullot and M.P. Schmidt, Physics of amorphous silicon-carbon alloys // phys. status solidi $(b), \mathbf{1 4 3}$, p. 345 (1987).

26. S. Ray, D. Das, A.K. Barua Infrared vibrational spectra of hydrogenated amorphous silicon carbide thin films prepared by glow discharge // Solar Energy Materials, 15, p. 45-57 (1987).

27. F. Demichelis, F. Giorgis, C.F. Pirri, E. Tresso Bonding structure and defects in wide band gap a$\mathrm{Si}_{1-\mathrm{x}} \mathrm{C}_{\mathrm{x}}: \mathrm{H}$ films deposited in $\mathrm{H}_{2}$ diluted $\mathrm{SiH}_{4}+\mathrm{CH}_{4}$ gas mixtures // Phil. Mag. B, 71(5), p. 1015-1033 (1995).

28. S.W. King, M. French, J. Bielefeld, W.A. Lanford, Mass and bond density measurements for PECVD $\mathrm{a}-\mathrm{SiC}_{\mathrm{x}}: \mathrm{H}$ thin films using Fourier transforminfrared spectroscopy // J. Non-Cryst. Solids, 357, p. 2970-2983 (2011).

29. J.H. Chen, W.J. Sah, Si.Ch. Lee, Identification of infrared absorption peaks of amorphous silicon carbon hydrogen alloy prepared using ethylene // $\mathrm{J}$. Appl. Phys. 70(1), p. 125-130 (1991).

30. S. Sahli, Y. Segui, S. Ramdani, and Z. Takkouk, R.f. plasma deposition from hexamethyldisiloxaneoxygen mixture // Thin Solid Films, 250, p. 206 (1994).

31. Y.S. Mor, T.C. Chang, P.T. Liu et al., Effective repair to ultra-low-k dielectric material $(k \sim 2.0)$ by hexamethyldisilazane treatment // J. Vac. Sci. Technol. B, 20(4), p. 1334-1338 (2002).

32. A. Singh, E.A. Davis, The $a-\mathrm{SiO}_{\mathrm{x}}: \mathrm{H}_{\mathrm{y}}$ thin film system. I. Structural study by IR spectroscopy // J. Non-Cryst. Solids, 122, p. 223-232 (1990).

33. B.H. Stuart, Infrared Spectroscopy: Fundamentals and Applications. Wiley, 2004.

34. T.R. Crompton, The Chemistry of Organic Silicon Compounds. Wiley, New York, 1989, p. 416-421.

35. M.L. Hair, Hydroxyl groups on silica surface // J. Non-Cryst. Solids, 19, p. 299-309 (1975).

36. A. Goullet, C. Valle, A. Granier, and G. Turban, Optical spectroscopic analyses of $\mathrm{OH}$ incorporation into $\mathrm{SiO}_{2}$ films deposited from $\mathrm{O}_{2}$ /tetraethoxysilane plasmas // J. Vac. Sci. Technol. A, 18(5), p. 2452 (2000).

37. D.D. Burkey, K.K. Gleason, Structure and mechanical properties of thin films deposited from 1,3,5-trimethyl-1,3,5-trivinilciclotrisiloxane and water // J. Appl. Phys. 93, p. 5143 (2003).

38. K. Maex, M.R. Baklanov, D. Shamiryan, F. Iakopi, S.H. Brongersma, and Z.S. Yanovitskaya, Low dielectric constant materials for microelectronics // J. Appl. Phys. 93, p. 8793 (2003).

39. E. Gat, B. Cros, R. Berjoan, and J. Durand, Low-frequency glow-discharge hydrogenated amorphous silicon carbide films // Materials and Manufacturing Processes, 7(3), p. 345-361 (1992).

40. R.S. Sussmann, R. Ogden, Photoluminescence and optical properties of plasma-deposited amorphous $\mathrm{Si}_{\mathrm{x}} \mathrm{C}_{1-\mathrm{x}}$ alloys // Phil. Mag. B, 44(1), p. 137-158 (1981). 
41. B.J. Baliga, Silicon Carbide Power Devices. World Scientific Publishing Co. Pte. Ltd., Singapore, 2005.

42. A.V. Vasin, Sh. Muto, Yu. Ishikawa, A.V. Rusavsky, T. Kimura, V.S. Lysenko, A.N. Nazarov, Comparative study of annealing and oxidation effects in $\mathrm{SiC}: \mathrm{H}$ and $\mathrm{a}-\mathrm{SiC}$ thin films deposited by radiofrequency magnetron sputtering techniques // Thin Solid Films, 519(7), p. 2218-222 (2011).

43. T. Friessnegg, M. Boudreau, P. Mascher, A. Knights, P.J. Simpson, W. Puff, Defect structure of carbon rich a-SiC:H films and the influence of gas and heat treatments // J. Appl. Phys. 84(2), p. 786 (1998).

44. L. Skuja, Optically active oxygen-deficiencyrelated centers in amorphous silicon dioxide // J. Non-Cryst. Solids, 239, p. 16-48 (1998).
45. Sh.N. Baker and G.A. Baker, Luminescent carbon nanodots: Emergent nanolights // Angew. Chem. Int. Ed. 49, p. 6726 (2010).

46. Haitao Li, Zhenhui Kang, Yang Liu and ShuitTong Lee, Carbon nanodots: Synthesis, properties and applications // J. Mater. Chem. 22, p. 24230 (2012).

47. Liping Lin, Mingcong Rong, Feng Luo, Dongmei Chen, Yiru Wang, Xi Chen, Luminescent graphene quantum dots as new fluorescent materials for environmental and biological applications // Trends in Analyt. Chem. 54, p. 83-102 (2014).

48. Jing-Liang Li, Bin Tang, Bing Yuan, Lu Sun, XunGai Wang, A review of optical imaging and therapy using nanosized grapheme and graphene oxide // Biomaterials, 34(37), p. 9519-9534 (Dec. 2013). 